\title{
The Effect of Using Cement Kiln Dust as a Partial Replacement of Cement on The Mechanical Properties of Concrete: Review and Modelling
}

\author{
Nawdar Sabir Faraj \\ Department of Civil Engineering \\ College of Engineering \\ University of Sulaimani \\ Sulaimani, Iraq \\ eng.nawdar@gmail.com
}

\author{
Dr. Mahdi Osman Hassun \\ Department of Civil Engineering \\ College of Engineering \\ University of Sulaimani \\ Sulaimani, Iraq \\ mahdi.hassun@univsul.edu.iq
}

\section{Article Info \\ Volume 5 - Issue 2 - \\ December 2020 \\ DOI: \\ 10.24017/science.2020.2.9 \\ Article history:}

Received :1 December 2020

Accepted : 22 December 2020

\section{Keywords:}

Cement Kiln Dust (CKD), Mechanical Properties,

Concrete, Cement,

Replacement.

\begin{abstract}
There have been many efforts in reusing Cement Kiln Dust (CKD), a by-product of cement manufacturing, in various areas of civil works. These efforts have been made due to the necessity of the material for proper disposal, because of its very fine texture and the fact that if not handled properly, it will be harmful to human health and the environment. Numerous studies have been conducted to investigate the effects of incorporating CKD in concrete as an approach of reusing it. In the current study, the effect of using cement kiln dust on the mechanical properties of concrete as a partial replacement of cement was reviewed. The investigated mechanical properties were compressive strength for the curing ages of 7 and 28 days and tensile and flexural strengths, modulus of elasticity, and water absorption for the curing age of 28 days. It was concluded that replacing cement with CKD leads to detrimental effects on all mechanical properties of concrete. There were sufficient amount of data to establish correlations between the amount of cement replacement with CKD, and its effect on all mechanical properties of concrete except for water absorption. Regression analyses were performed and model equations with acceptably high R2s were prepared. The optimal CKD content regarding all mechanical properties was concluded to be $10 \%$ by the cement weight, at which 7 and 28 days compressive strengths, 28 days tensile and flexural strengths, and elastic modulus decreased by amounts of $11 \%, 12 \%, 8 \%, 9 \%$, and $8 \%$ respectively.
\end{abstract}

Copyright ( 2020 Kurdistan Journal of Applied Research. All rights reserved. 


\section{INTRODUCTION}

In the production line of Portland cement, a large quantity of dust is produced, known as cement kiln dust (CKD). CKD is considered an industrial waste, being a by-product of cement production [1].

In cement production, a mixture of limestone, clay, sand, and shale are mixed in controlled quantities and milled together as water slurry in wet process or a dry blend in dry process kilns. After entering the upper part of the rotary kiln, the ground mixture travels down the kiln headed for the burner zone. When the Kiln charge reaches the temperature of fusion, clinker in the shape of small-size balls, semi-finish dust, and fine solid particles are formed. CKD is generated during the operation, which is unstable and fine enough that the hot gases will carry it out of the kiln [2]. Filters at the end of the dust chambers capture $98-100 \%$ of the generated dust. In both wet and dry processes, there are two approaches to handle CKD, either by returning part of it to the kiln from the cyclone (the system of dust collection) or collecting it from the filters for disposal or recycling purposes [3].

\subsection{Physical Properties:}

CKD is a fine powder with relatively uniform size, comprised of a blend of partially calcined, raw feed cement clinker and condensed volatile salts. CKD has more amount of fine particles than cement $[4,5]$. Some common physical properties of CKD are summarized in Table (1).

Table 1: Common physical properties of CKD [5].

\begin{tabular}{ll}
\hline Property & Value \\
\hline Gradation (75\% Passing) & $0.030 \mathrm{~mm}$ (No. 450 sieve) \\
\hline Maximum particle size & $0.300 \mathrm{~mm}$ (No. 50 sieve) \\
\hline Specific surface (cm $\left.{ }^{2} / \mathbf{g}\right)$ & $4,600-14,000$ \\
\hline Specific gravity & $2.6-2.8$ \\
\hline
\end{tabular}

\subsection{Chemical Properties:}

The chemical formation of CKD resembles that of conventional Portland cement. It is mainly comprised of compounds of silica, lime, alumina, and iron. The chemical formation of CKD is dependent upon the raw materials used in clinker production and on the carbon-based fuel's source and type, which is used in heating the materials in the kiln [6]. High concentrations of free lime are present in CKD in the collected coarse particles that are nearest to the kiln. Finer particles contain higher sulfates and alkali concentrations.

The dust will contain more free lime if the coarser particles are not filtered and directed back to the kiln. CKD from wet process kilns contains less calcium content than those collected from dry-process kilns. After X-ray diffraction analysis the kiln dust is observed to contain limestone as the main constituent, a small amount of quartz together with $\mathrm{CaSO} 4, \mathrm{NaCl}, \mathrm{K} 2 \mathrm{SO} 4$, spurite [2(C2S) $\cdot \mathrm{CaCO} 3]$ and sulphospurite [2(C2S) $\mathrm{CaSO} 4][3,5]$. The typical chemical formation for CKD in comparison with typical OPC is summarized in Table 2. Generally, the CKD water mixtures have a gas $\mathrm{PH}$ of around 12. It is considered caustic due to its significant alkalis content. In concentrations less than $0.05 \%$ by weight, trace metals such as lead, cadmium, radionuclides, and selenium are generally found in CKD [3]. 
Table 2: Typical chemical composition of CKD and Portland cement [7].

\begin{tabular}{lll}
\hline Constituent & CKD (\%) & OPC (\%) \\
\hline SiO2 & $11-16$ & 22 \\
\hline Al2O3 & $3-6$ & 5 \\
\hline Fe2O3 & $1-4$ & 3 \\
\hline CaO & $38-50$ & 64 \\
\hline MgO & $0-2$ & 1 \\
\hline SO3 & $4-18$ & 3 \\
\hline K2O & $3-13$ & $<1$ \\
\hline Na2O & $0-2$ & $<1$ \\
\hline Cl & $0-5$ & $<0.1$ \\
\hline Loss on Ignition & $5-25$ & 1 \\
\hline Free CaO & $1-10$ & 2 \\
\hline
\end{tabular}

\subsection{Environmental and health aspects:}

The energy lost in CKD is estimated by the UK cement industry to be an annual $\mathrm{CO}_{2}$ emission of 80 Kilotons, which is a figure that increases with the increase in consumption of cement [4]. Due to its high fineness and chemical formation, CKD is considered a harmful material for human health, which can be inhaled after being carried around by the wind if not handled properly. For people who are in exposure to it, CKD can cause numerous health problems, namely, lung function impairment, restrictive lung disease, chronic obstructive lung disease, pneumoconiosis, and cancer of the lungs, colon, and stomach. Other studies show that cement dust can enter the systemic circulation of the body and reach all body organs affecting different tissues including bone, liver, heart, spleen, muscles, and hair and at the end, affecting physiological performance by affecting their microstructure [8]. Disposal of CKD on dry landfills can cause the dispersion of the dust and being carried by the wind, which is why it is usually disposed of by pouring it into pre-prepared swamps or hydrating it before disposal. The former can adversely influence the quality of underground waters if not done with care [8].

\subsection{Recycling CKD:}

The annual amount of cement production in 2017 worldwide, was 4.99 billion tons [9, 10]. Meanwhile, the rate of CKD production was in a range between 54 to $200 \mathrm{~kg}$ per ton of produced cement clinker. This means that the worldwide annual production rate of CKD was between 269 million to 1.1 Billion tons [11].

Cement kiln dust can be reused in various ways, most commonly by returning it to the cement production cycle. It is also used in soil stabilization, as cement replacement in cement products, waste treatment, and asphalt pavement [12].

The most efficient recycling way of CKD is reusing it in the cement manufacturing process. However, this is not always applicable in some plants. In addition, the amount of CKD returned to the kiln is limited by restrictions on the alkalinity of the cement, which is constrained to $0.6 \%$ by most of the international specifications. From the alkali aspect, if the alkali level of cement is allowed to be raised by around $0.1 \%$, it is estimated that most of the CKD could be used in the process of clinker production. Although in addition to that, the restrictions on the required chloride concentration on cement performance in reinforced concrete requires to be raised [3, 4]. 
Another way of reusing CKD is by using it as cement replacement in cement products as in mortar and concrete. Numerous studies have been conducted in the past years to investigate the influences of using cement kiln dust as a partial substitution of cement in concrete. However, none of the former studies has established correlations between the amounts of CKD with its effect on the mechanical properties of concrete. The current study was conducted to review and collect all available related literature data, find correlations between CKD replacement ratios versus the changes in the mechanical properties of CKD concrete, and prepare model equations accordingly after regression analysis.

\section{LITERATURE REVIEW}

The collected literature data in the current study were regarding compressive strength in 7 and 28 days of curing age, tensile strength, flexural strength, modulus of elasticity, and water absorption in 28 days of curing for concretes with no pozzolanic additives (no tertiary blends), in which the cement is replaced with CKD in different ratios.

Ravindrarajah [6] investigated compressive, flexural, and tensile strengths of concrete in which OPC cement was replaced with CKD by ratios of $15 \%, 25 \%$, 35\%, and $45 \%$ at curing ages of 3, 7, 14, 28, 56 and 90 days. Two groups of concrete batches were prepared with different mix proportions of 1:2:4, with $310 \mathrm{~kg}$ of OPC cement and water to binder ratio (w/b) of 0.65 , and $1: 1.5: 3$, with $390 \mathrm{~kg}$ of OPC cement and w/b of 0.5 . Results indicated that all mechanical properties of the samples decreased with the replacement of CKD. At the highest CKD replacement of $45 \%$, the 28 days compressive, tensile, and flexural strengths decreased by $45 \%, 60 \%$, and $56 \%$ in $1: 2: 4$ mixes and by $37 \%, 34 \%$, and $29 \%$ in the $1: 1.5: 3$ mixes respectively. The optimal amount of cement replacement with CKD for all batches was at $15 \%$ by the weight of cement. However, trends of strength loss were different for the batches. The amount of 7and 28 days compressive and 28 days tensile strength losses in the 1:2:4 batches were $8 \%, 6 \%$, and $2 \%$ respectively, which were better than the $1: 1.5: 3$ batch with strengths losses of $12 \%, 22 \%$, and $7 \%$ correspondingly. Nonetheless, the flexural strength decreases had an opposite trend. The decrease in flexural strength of the 1:2:4 batch was $21 \%$ while that of the 1:1.5:3 batch was only a $6 \%$ decrease at $15 \%$ cement replacement with CKD [6].

Shoaib, et al. [2] used CKD in three groups of concrete replacing three different types of ordinary Portland cement (OPC), blast furnace slag cement (BFSC), and sulfate resistant cement (SRC) at ratios of $10 \%, 20 \%, 30 \%$, and $40 \%$. The amount of cement used for the control samples of each group was $350 \mathrm{~kg}$, with a fixed w/b of 0.5 . Compressive and tensile strengths of all the batches were investigated at 28 days of curing. Results indicated that the compressive strength of the samples decreased with the replacement of CKD. At the highest CKD replacement of $40 \%$, the 28 days compressive strength decreased by 54\%, 56\%, and 57\% in OPC, BFSC, and SRC groups respectively. The optimal amount of CKD in terms of compressive strength was the lowest ratio of $10 \%$, at which the compressive strength of OPC, BFSC, and SRC groups decreased by amounts of 15\%,16\%, and 17\% respectively. Therefore, it can be concluded that the group with OPC cement exhibited the lowest impact in compressive strength when replaced with CKD and SRC group the highest. However, in tensile strength results, the trend was vice versa. The SRC group exhibited the lowest impact in tensile strength with a $9 \%$ strength decrease. Meanwhile, the drop in tensile strength of OPC was 15\%, which was the highest drop among the three groups. The BFSC replaced group exhibited a 12\% drop in tensile strength.

Udoeyo and Hyee [13] studied compressive, tensile, and flexural strength of concrete containing $270 \mathrm{~kg}$ of OPC cement replaced with CKD, in ratios of $20 \%, 40 \%, 60 \%$, and $80 \%$ of the cement weight. The curing ages at which the tests were performed were one, 3, 7, and 28 days. The w/b was fixed at 0.65 for all the batches. At the maximum CKD replacement of $80 \%$, the 28 days compressive, tensile, and flexural strengths of the samples decreased by $85 \%, 88 \%$, and $90 \%$. At the lowest CKD replacement of 20\%, the 7 and 28 days compressive strengths of concrete samples decreased by $22 \%$ and $8 \%$ respectively. 
28days tensile and flexural strengths also dropped by 22\% and 26\% correspondingly compared to the control group at $20 \%$ CKD content [13].

Al-Harthy, et al. [14] investigated the influence of CKD on the compressive and flexural strengths of concrete samples at the ages of (3, 7, and 28) days. Three groups of concrete batches with water-to-binder ratios of $0.50,0.60$, and 0.70 were prepared by substituting Portland cement with CKD in ratios of $0 \%$ (control), 5\%, 10\%, 15\%, 20\%, 25\%, and 30\% by the weight of cement. Results indicated that there were decreases in compressive strength as well as flexural strength with increases in CKD replacement for all batches in general. For all blends, the control mixture exhibited the highest compressive and flexural strength. The important observation was that there was less decrease in compressive strengths in mixes with lower water-to-binder ratios (0.50) than in those mixes with high water to binder ratios (0.6 and 0.7). At the highest CKD replacement of 30\%, the 28 days compressive strength of the samples with w/b s of $0.5,0.6$, and 0.7 decreased by $22 \%$, $29 \%$, and $32 \%$ respectively. The optimal CKD content was $5 \%$ for the groups with w/b of 0.7 and 0.6 , at which there were reductions of $11 \%$ and $15 \%$ in 7 days of curing and $9 \%$ and $13 \%$ in 28 days of curing respectively. Meanwhile, for the batch with water to binder ratios of 0.5 , the optimal amount was observed to be $15 \%$ at which the reduction rates in strength were only $8 \%$ and $6 \%$ for 7 and 28 days of curing respectively. The latter indicates that in concretes with low w/b ratios, the negative effect of CKD might be less, in comparison with concretes with higher water content. The flexural strength results demonstrated the same trend as with compressive strength results, showing an even higher impact of water content on the effect of CKD in concrete. The optimal CKD content for batches with water to binder ratios of $0.5,0.6$, and 0.7 , were $25 \%, 10 \%$, and $5 \%$ respectively at which the flexural strength reductions were $7 \%, 4 \%$, and $24 \%$ correspondingly [14].

Maslehuddin, et al. [1] used CKD in two groups of concrete, replacing different cement types of type I and type $\mathrm{V}$ in each group in ratios of $0 \%, 5 \%, 10 \%$, and $15 \%$ in each. Compressive strengths of the batches at 7 and 28 days were observed along with the difference in the effect of CKD on each group replacing each type of cement. It was concluded that the optimal amount for replacing type I cement with CKD in terms of compressive strength at ages of 7 and 28 was $5 \%$, at which no decrease in strength was observed. As for type V cement, the optimum amount of cement replacement was $15 \%$, at which there was only a $1 \%$ drop in compressive strength [1].

Hilal and Mohammad [15] Studied compressive, tensile, and flexural strengths and elastic modulus of concrete at ages of 7 and 28 days after replacing OPC cement with CKD at ratios of $(0,10,30$, and 50$) \%$. $390 \mathrm{Kg}$ of cement was used for the control group and the water to cement ratio of all batches was fixed at 0.45 . It was observed that at the highest CKD content of $50 \%$ the 28 days compressive, tensile, and flexural strengths and elastic modulus decreased by amounts of $40 \%, 4 \%, 54 \%$, and $54 \%$ respectively compared to the strengths of their control groups. The optimal amount was $10 \%$ for 7 and 28 days compressive strengths and 28 days flexural strength, at which decreases of $12 \%, 20 \%$, and $30 \%$ were observed respectively.

The data of tensile strength, on the other hand, demonstrated very non-significant changes even in the highest replacement ratio of 50\%, at which the tensile strength decreased by only $4 \%$. Regarding elastic modulus property of the batches, the optimal CKD content was 30\%, at which only a $9 \%$ decrease was observed compared to the control group.

H Hassan, et al. [16] investigated the effect of CKD on compressive and tensile strengths of concrete after replacing OPC cement with $(5,10,15,20,25$, and 30) percent by weight. An amount of $390 \mathrm{Kg}$ of cement was used for the control group and the w/b was fixed at 0.40 for all batches. At the highest CKD replacement of 30\%, the 28 days compressive and tensile strengths of the samples decreased by $35 \%$ and $25 \%$ respectively. The optimal CKD content was observed to be $10 \%$ at which there were decreases of $3 \%, 9 \%$, and $4 \%$ for 7 days compressive, 28 days compressive, and 28 days tensile strengths respectively [16]. 
Abdulabbas [17] used two types of cement, OPC and SRC in two groups, and studied the compressive strength, tensile strength, and water absorption of both groups by replacing the cement with CKD at $10 \%$ and $20 \%$ in each. $405 \mathrm{~kg}$ of cement was used in this study with a fixed w/b of 0.47 . At the highest CKD content of $20 \%$, there were $64 \%$ and $72 \%$ decreases in compressive and tensile strength respectively in the SRC group and a decrease of $65 \%$ in both compressive and tensile strength in the OPC group. Compressive strength at ages of 7 and 28 days and tensile strength at age of 28 days decreased substantially by amounts of $46 \%$, 37\%, and $33 \%$ respectively after replacing only $10 \%$ of cement with CKD in the OPC group. The water absorption also increased by $17 \%$ at $10 \%$ cement replacement with CKD. The results of the SRC group showed a worse trend compared to OPC, in which 7 and 28 days compressive strengths and 28 days tensile strength decreased by $47 \%$, $41 \%$, and $31 \%$ respectively at $10 \%$ CKD, while the water the absorption increased by $21 \%$ [17].

Siddique and Rajor [18] studied the effect of non-treated and bacterial treated cement kiln dust on compressive strength and water absorption of concrete at ages of 7, 28 days after alkalinity reduction. OPC cement was replaced with treated and normal and CKDs at ratios of $0 \%, 5 \%$, $10 \%$, and $15 \%$. The w/b was fixed at 0.5 . $396 \mathrm{Kg}$ cement was used in the control group. It was concluded that the compressive strength increased by $5 \%$ and $4 \%$ at 7 and 28 days respectively after replacing $10 \%$ amount of cement with normal CKD and was equal to the control at $15 \%$ replacement, which is contrary to the literature data. The water absorption decreased with increasing CKD content up to the optimal amount of $10 \%$, at which the water absorption decreased by $55 \%$ compared to the control group, which is also contrary to the results of Abdulabbas [17] and expectations [18].

Najim, et al. [19] produced high-performance self-compact concrete, incorporating CKD as a partial replacement for cement with ratios of $10 \%, 20 \%$, and $30 \%$. An amount of $450 \mathrm{~kg}$ of OPC cement was used for the control group with fixed water to cement ratio of 0.32 for all batches. $11 \mathrm{~kg}$ of superplasticizer was used in all batches for enhancing workability. Compressive and tensile strengths along with elastic modulus at 28 days of curing were observed. At the highest CKD replacement of $30 \%$, the compressive and tensile strengths and the elastic modulus decreased by $29 \%$, 24\%, and $24 \%$ respectively. The optimal amount of cement replacement for CKD was $10 \%$ at which the 28 days compressive strength, tensile strength, and modulus of elasticity exhibited $6 \%, 20 \%$, and $9 \%$ decreases correspondingly compared to the control group [19].

Gamil, et al. [20] investigated the compressive and flexural strength properties of concrete at 7 and 28 days, in which OPC cement was replaced with CKD in ratios of $0 \%$ to $100 \%$, with fixing $\mathrm{w} / \mathrm{b}$ at 0.45 . They used two CKD types of normal and treated with heat. It was concluded that replacing cement with both types of normal and treated CKD had detrimental effects on compressive and strengths in both ages of $7 \& 28$ days. The 28 days compressive strength decreased by $63 \%$ and $82 \%$ at CKD replacements of $50 \%$ and $100 \%$ respectively. The 28 days flexural strength decreased by $56 \%$ and $83 \%$ at $50 \%$ and $100 \%$ CKD replacements. The optimal amount of cement replacement with normal CKD was 10\% in all cases, at which, $23 \%$ and $9 \%$ decreases were observed in compressive and flexural strengths respectively with normal CKD [20]. 


\section{METHODS}

Different results were achieved in the literature on the effects of replacing cement with CKD on the mechanical properties of concrete. After collecting data from all the results of the discussed literature, regression analyses were performed and graph models were prepared, which are presented in this section.

\subsection{Data Collection}

There was a sufficient amount of data on 7 and 28 days compressive strengths, 28 days tensile and flexural strengths, and elastic modulus to establish correlations between the amounts of CKD replacement and the changes in the mentioned mechanical properties compared to their control groups. However, the data on water absorption were limited to only two studies (Abdulabbas [17] and Siddique and Rajor [18]), whose data had opposite trends. Therefore, in the current study, only a scatterplot of the data is presented and none is relied upon for conclusions. Figures 1 to 6 depict the scatterplot for the relation of CKD replacement, with the ratio of the mechanical properties of the CKD concrete samples over the mechanical properties of their corresponding control groups.

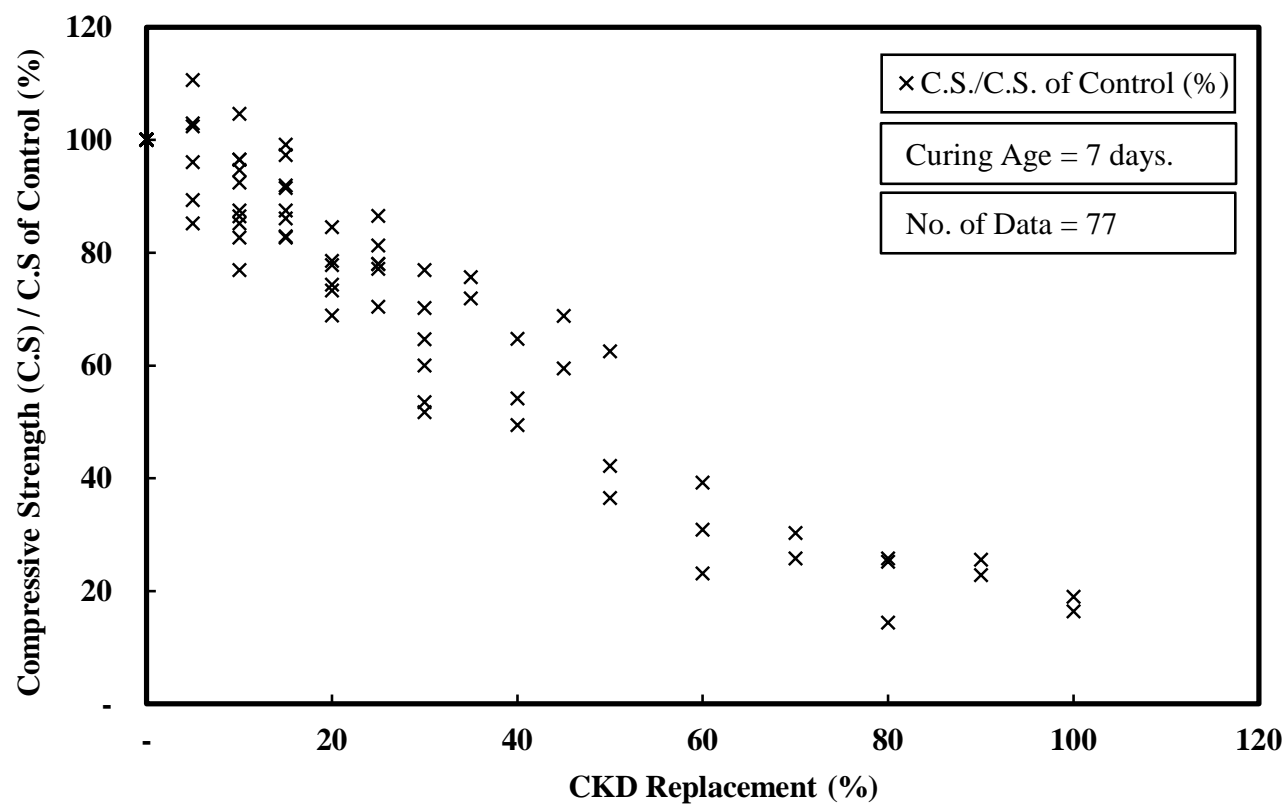

Figure 1: Scatterplot of the literature data, showing relations between CKD replacement in (\%), and the ratio of 7 days compressive strength of the literature to their corresponding control groups in (\%). 


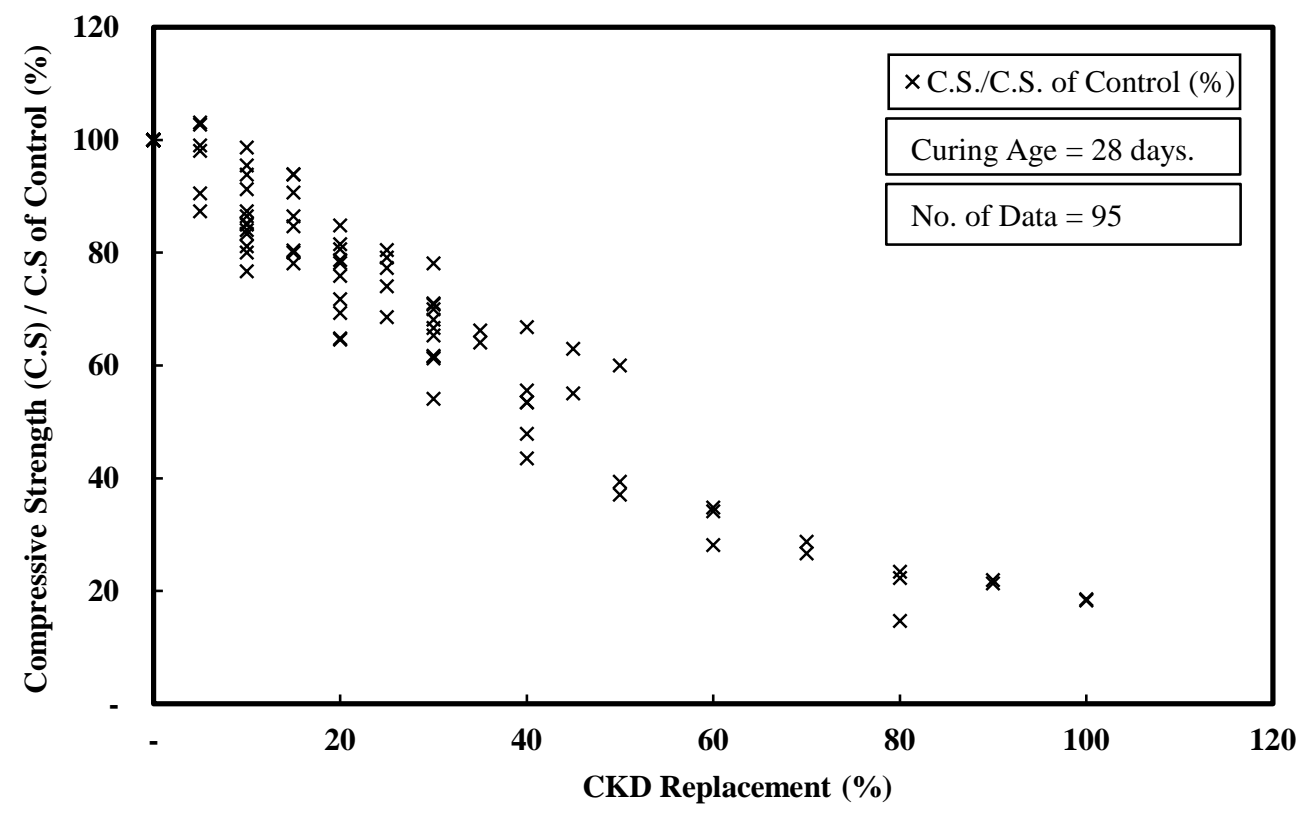

Figure 2: Scatterplot of the literature data, showing relations between CKD replacement in (\%), and the ratio of 28 days compressive strength of the literature to their corresponding control groups in (\%).

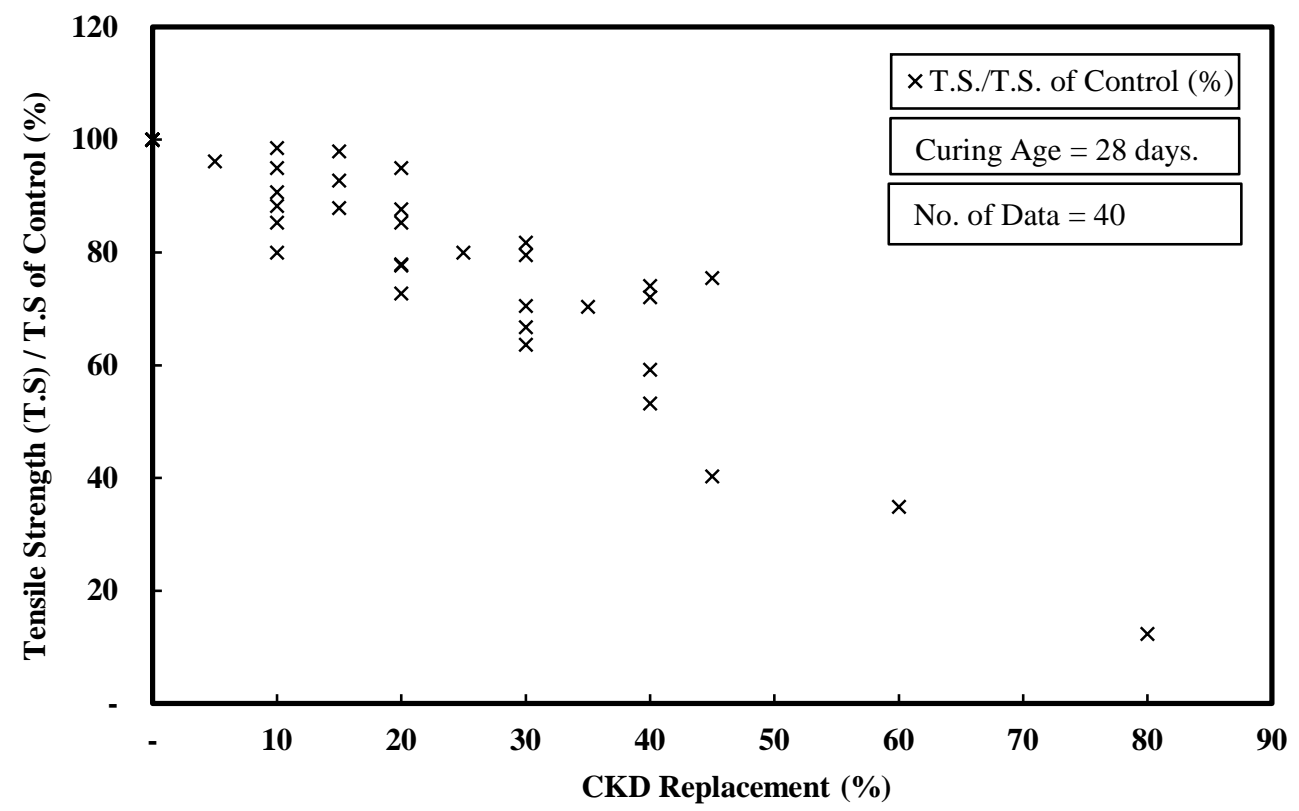

Figure 3: Scatterplot of the literature data, showing relations between CKD replacement in (\%), and the ratio of 28 days tensile strength of the literature to their corresponding control groups in (\%). 


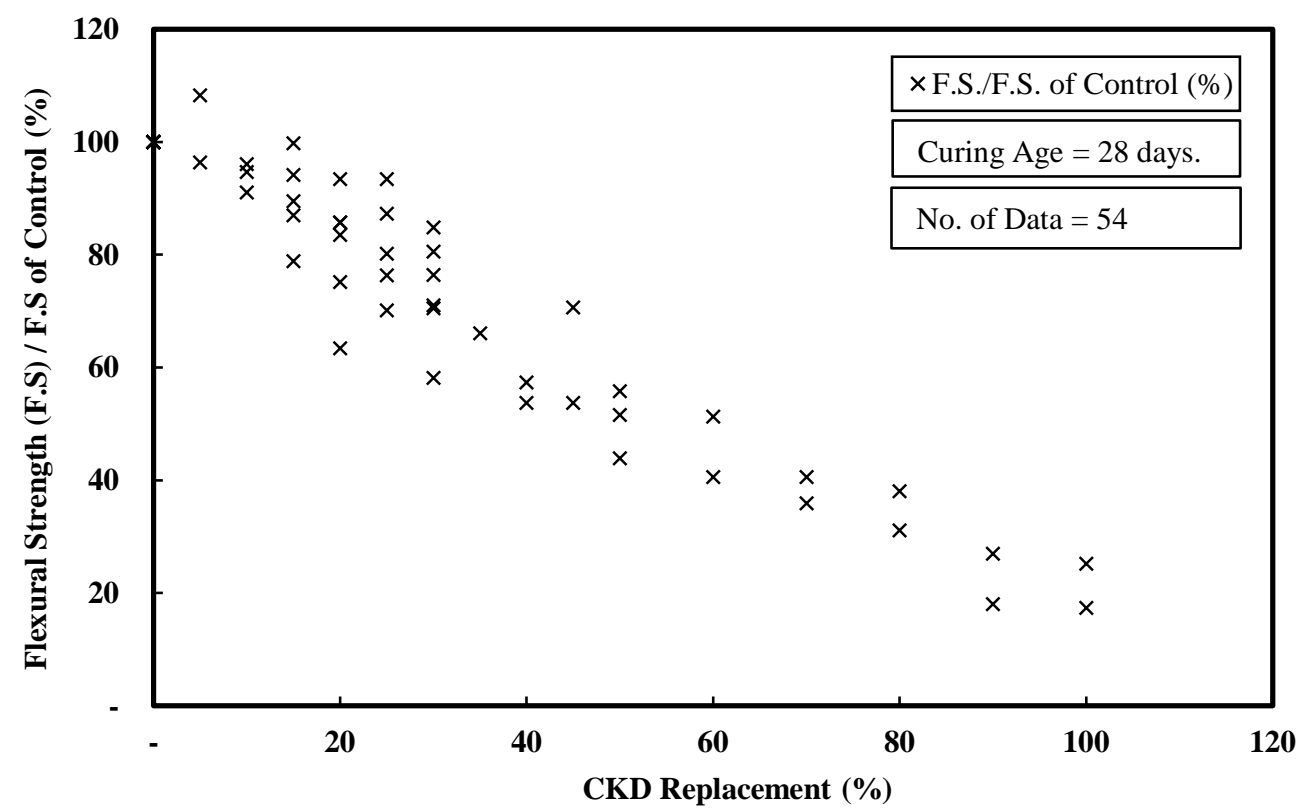

Figure 4: Scatterplot of the literature data, showing relations between CKD replacement in (\%), and the ratio of 28 days flexural strength of the literature to their corresponding control groups in (\%).

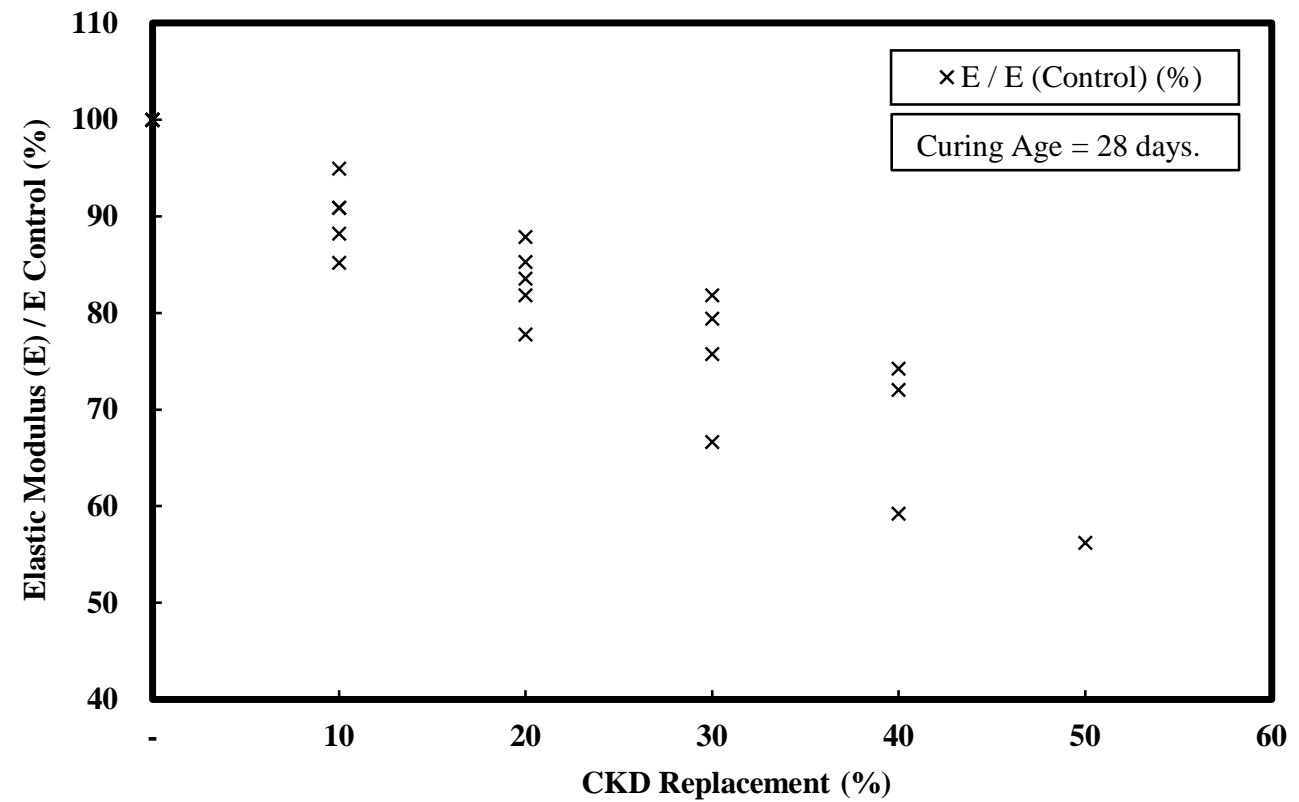

Figure 5: Scatterplot of the literature data, showing relations between CKD replacement in (\%), and the ratio of 28 days elastic modulus of the literature to their corresponding control groups in (\%). 


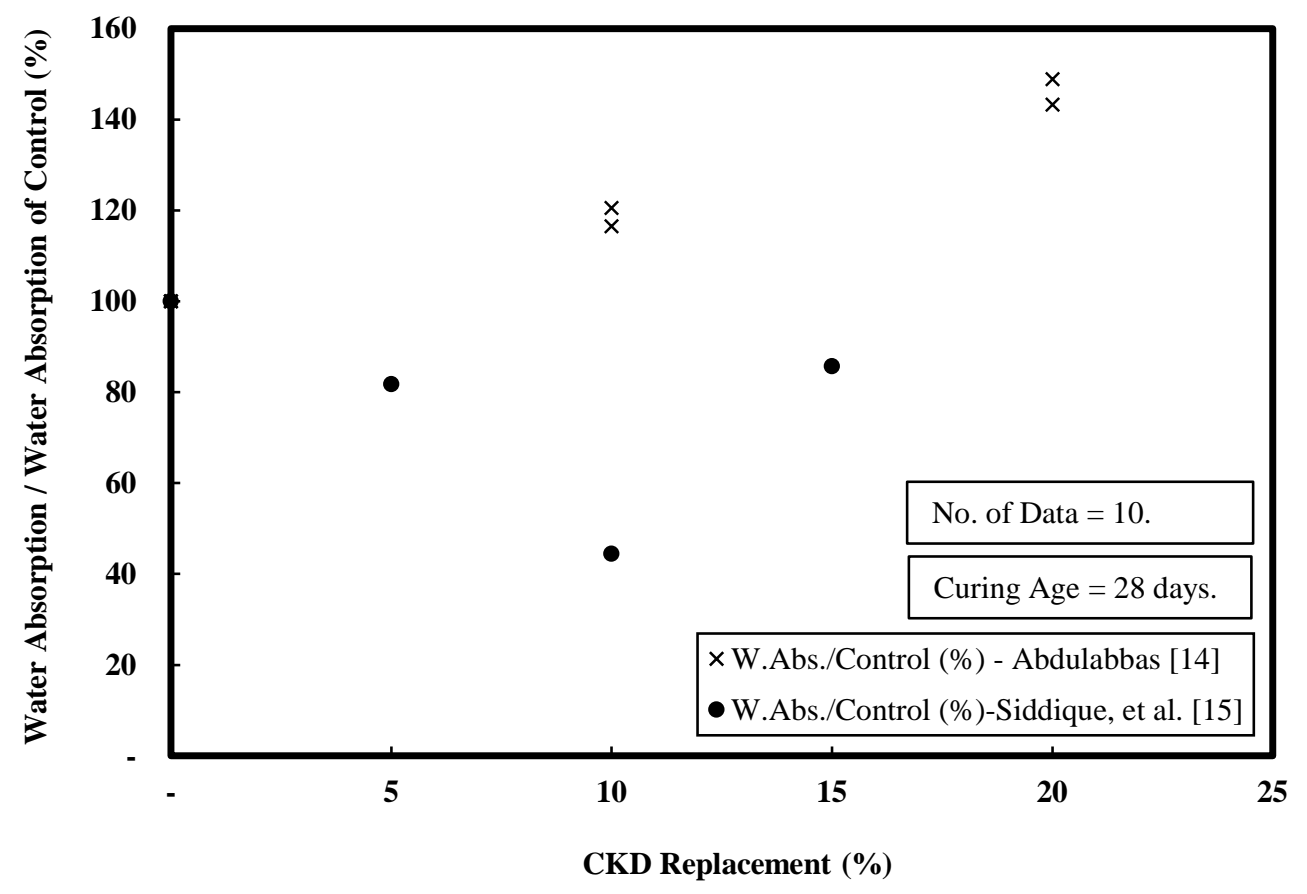

Figure 6: Scatterplot of the literature data, showing relations between CKD replacement in (\%), and the ratio of 28 days water absorption of the literature to their corresponding control groups in (\%).

\subsection{Regression Analysis:}

After performing regression analyses for the collected data using Minitab and Microsoft Excel programs, models were prepared to predict the correlations between the amounts of cement replacement with CKD, versus the ratio of the mechanical properties of the CKD concrete samples over the properties of their corresponding control groups.

The best trend equation for all models was the $2^{\text {nd }}$-degree polynomial, in which the coefficients of determination $\left(\mathrm{R}^{2}\right)$ were at the highest for all the properties. The prepared polynomial equation is shown in equation (1).

$$
y=a x^{2}+b x+100
$$

Where:

$\mathrm{y}=$ Mechanical properties of CKD concrete samples/Mechanical properties of the corresponding control group in percentage.

$\mathrm{x}=$ Amount of cement replaced with CKD in percentage.

a \& b = Model parameters. 
In order to determine the accuracy of the predicted model, coefficient of determination $\left(\mathrm{R}^{2}\right)$ and root mean square error (RMSE) were used as defined in equations (2) and (3).

$$
\begin{aligned}
R^{2} & =1-\left(\frac{\sum\left(y_{i}-x_{i}\right)^{2}}{\sum\left(y_{i}-\bar{y}\right)^{2}}\right) \\
R M S E & =\sqrt{\frac{\sum_{i=1}^{n}\left(y_{i}-x_{i}\right)^{2}}{N}}
\end{aligned}
$$

$N=$ number of data points.

$\bar{y}=$ mean of the collected data.

$\bar{x}=$ mean of the calculated values.

$y_{i}=$ collected data from the literature.

$x_{i}=$ calculated value from the model .

Table 3 summarizes the regression analysis results for all the mechanical properties in the literature.

Table 3: Statistical \& regression analysis data for the mechanical properties

\begin{tabular}{ccccccccc}
\hline $\begin{array}{c}\text { Dependent } \\
\text { Variable } \\
\text { (Y-Axis) }\end{array}$ & $\begin{array}{c}\text { Independent } \\
\text { Parameter } \\
\text { (X-Axis) }\end{array}$ & Equation & A & B & RMSE & $\mathbf{R}^{2}$ & $\begin{array}{c}\text { No. } \\
\text { of } \\
\text { Data }\end{array}$ & $\begin{array}{c}\text { Fig } \\
\text { No. }\end{array}$ \\
\hline $\begin{array}{c}\text { 7d C.S/ } \\
\text { C.SControl (\%) }\end{array}$ & CKD (\%) & $y_{e}=a x^{2}+b x+100$ & 0.0024 & -1.1253 & 7.73 & 0.91 & 77 & $(7)$ \\
\hline $\begin{array}{c}\mathbf{2 8 d} \text { C.S/ } \\
\text { C.SControl (\%) }\end{array}$ & CKD (\%) & $y_{e}=a x^{2}+b x+100$ & 0.0038 & -1.2519 & 6.05 & 0.94 & 95 & $(8)$ \\
\hline $\begin{array}{c}\mathbf{2 8 d} \text { T.S/ } \\
\text { T.SControl (\%) }\end{array}$ & CKD (\%) & $y_{e}=a x^{2}+b x+100$ & -0.0046 & -0.7359 & 6.95 & 0.88 & 40 & $(9)$ \\
\hline $\begin{array}{c}\mathbf{2 8 d} \text { F.S/ } \\
\text { F.SControl (\%) }\end{array}$ & CKD (\%) & $y_{e}=a x^{2}+b x+100$ & 0.0012 & -0.9452 & 6.99 & 0.92 & 54 & $(10)$ \\
\hline $\begin{array}{c}\mathbf{2 8 d} \text { E/ } \\
\text { EControl (\%) }\end{array}$ & CKD (\%) & $y_{e}=a x^{2}+b x+100$ & 0.007 & -0.8484 & 4.1 & 0.9 & 24 & $(11)$ \\
\hline
\end{tabular}




\section{RESULTS AND DISCUSSION}

\subsection{Compressive Strength}

\subsubsection{Days Compressive Strength}

According to the literature data, the 7 days compressive strength of CKD samples compared to the control group, decreased in percentage almost at the same rate as increasing the amount of CKD replacement in general. Figure 7 shows the trend line derived from the prepared model equation after regression of the data, which had an $\left(\mathrm{R}^{2}\right)$ of 0.91 , which exhibits acceptable accuracy. It was observed that the optimal amount of CKD replacement for 7 days compressive strength is $10 \%$ at which the loss in strength is $11 \%$, as summarized in Table 4.

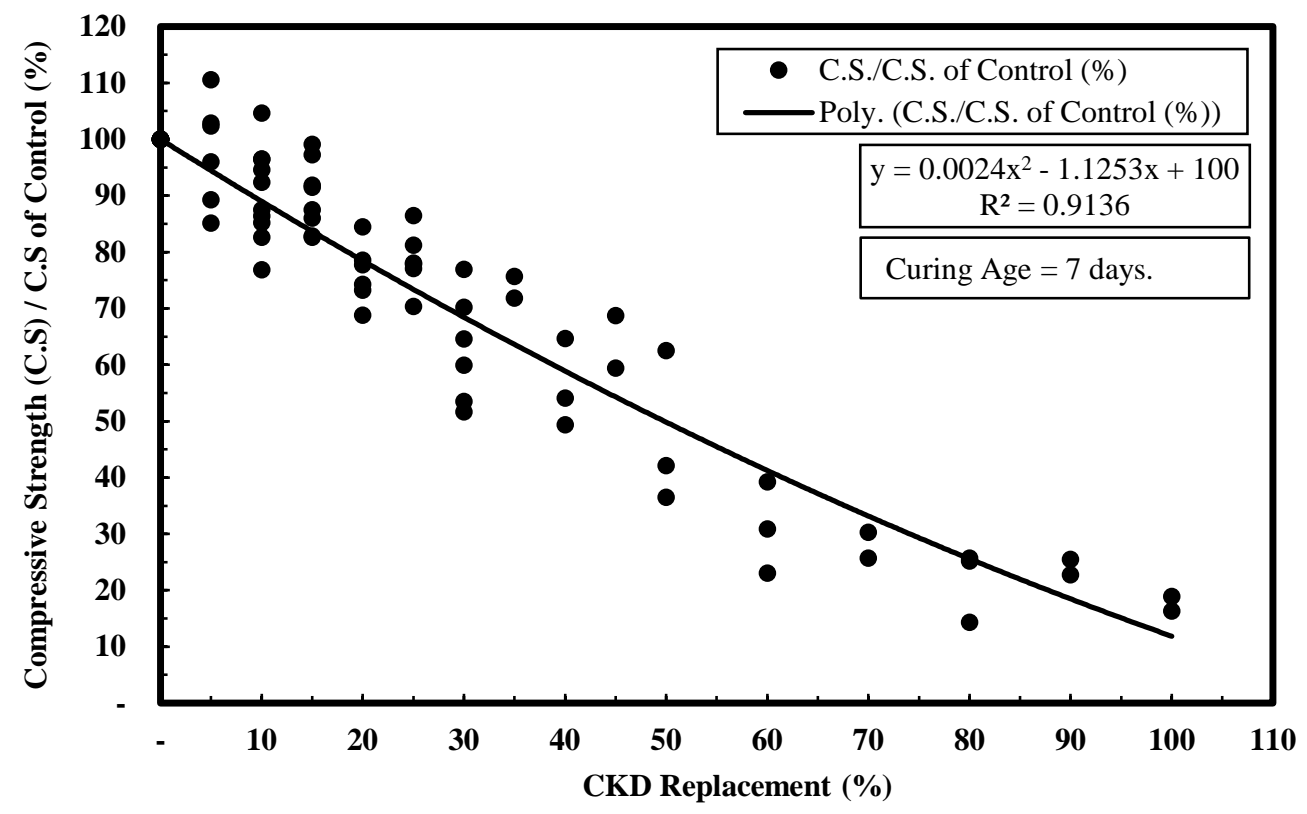

Figure 7: Trend line of the prepared model equation for CKD replacement in (\%), versus the ratio of 7 days C.S. of CKD concrete samples in literature, to their corresponding control groups in (\%).

Table 4: 7 days compressive strength reduction in CKD concretes up to 50\% CKD replacement amount, according to the prepared model equation.

\begin{tabular}{ll}
\hline CKD Replacement & $\begin{array}{l}\text { 7 Days Compressive Strength Reduction in CKD } \\
\text { Samples According to The Prepared Model Equation }\end{array}$ \\
\hline $\mathbf{5 \%}$ & $6 \%$ \\
\hline $\mathbf{1 0 \%}$ & $11 \%$ \\
\hline $\mathbf{1 5 \%}$ & $16 \%$ \\
\hline $\mathbf{2 0 \%}$ & $22 \%$ \\
\hline $\mathbf{2 5 \%}$ & $27 \%$ \\
\hline $\mathbf{3 0 \%}$ & $32 \%$ \\
\hline $\mathbf{3 5 \%}$ & $36 \%$ \\
\hline $\mathbf{4 0 \%}$ & $41 \%$ \\
\hline $\mathbf{4 5 \%}$ & $46 \%$ \\
\hline $\mathbf{5 0} \%$ & $50 \%$
\end{tabular}




\subsubsection{Days Compressive Strength}

The prepared model for the 28 compressive strength data had an $\mathrm{R}^{2}$ of 0.94 , which means that the model trend line is of good accuracy. The 28 days compressive strength losses in CKD samples were slightly more than 7 days as depicted in Figure 8. The optimal amount of CKD replacement also can be considered as $10 \%$, at which the strength loss is at $12 \%$, which is $1 \%$ more than that of 7 days compressive strength at this amount of CKD replacement. Table 5 summarizes the amounts of strength losses up to $50 \%$ of CKD replacement.

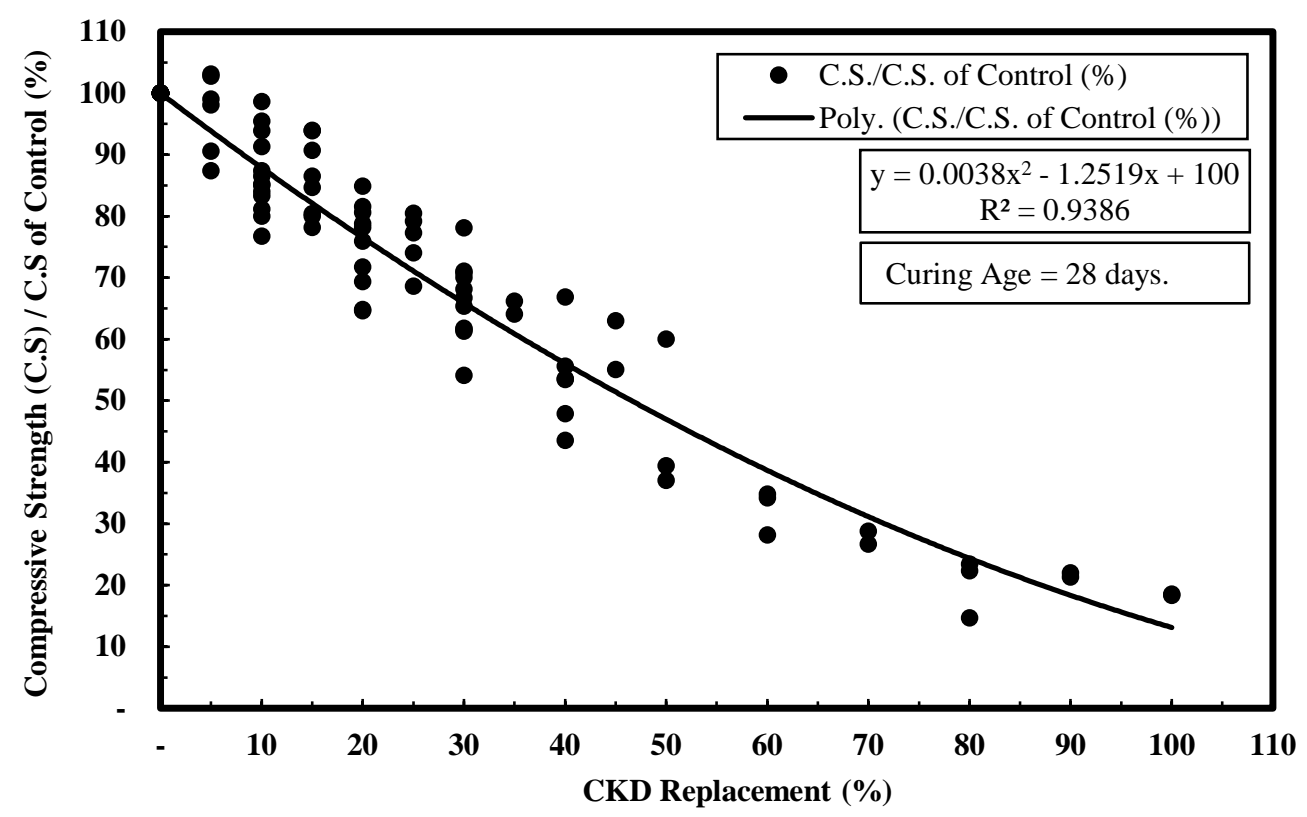

Figure 8: Trend line of the prepared model equation for CKD replacement in (\%), versus the ratio of 28 days C.S. of CKD concrete samples in literature, to their corresponding control groups in (\%).

Table 5: 28 days compressive strength loss in CKD concrete up to 50\% CKD replacement amount according to the prepared model equation.

\begin{tabular}{ll}
\hline CKD Replacement & $\begin{array}{l}\text { 28 Days Compressive Strength Loss in CKD Samples } \\
\text { According to The Prepared Model Equation }\end{array}$ \\
\hline $\mathbf{5 \%}$ & $6 \%$ \\
\hline $\mathbf{1 0} \%$ & $12 \%$ \\
\hline $\mathbf{1 5 \%}$ & $18 \%$ \\
\hline $\mathbf{2 0} \%$ & $24 \%$ \\
\hline $\mathbf{2 5 \%}$ & $29 \%$ \\
\hline $\mathbf{3 0} \%$ & $34 \%$ \\
\hline $\mathbf{4 0} \%$ & $39 \%$ \\
\hline $\mathbf{4 5 \%}$ & $44 \%$ \\
\hline $\mathbf{5 0} \%$ & $49 \%$ \\
\hline
\end{tabular}




\subsection{Days Tensile Strength}

The prepared model for the 28 days tensile strength data had an $\mathrm{R}^{2}$ of 0.88 , which means that the accuracy of the model trend is lower than that of compressive strength models. This is because all the tests in the literature were indirect tensile strength test (ASTM D6931 - 17), which in its own nature has a lower accuracy than compressive or even flexural strength test results. The losses in 28 days tensile strength in CKD samples were less than that of compressive strength property and had an inverse trend line in comparison as depicted in Figure 9. The optimal amount of CKD replacement can be considered as $10 \%$ at which the strength loss was at $8 \%$. The amounts of strength losses up to $50 \%$ of CKD replacement are summarized in Table 6.

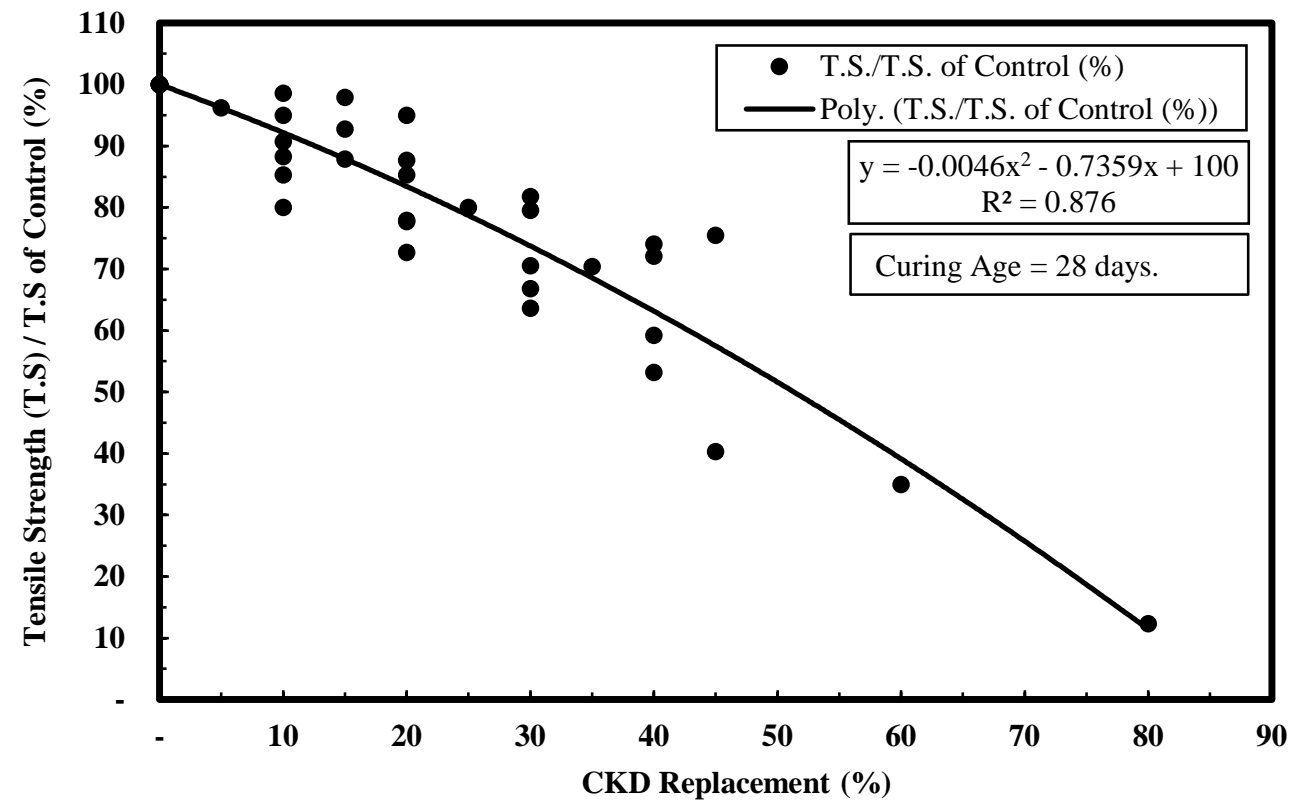

Figure 9: Trend line of the prepared model equation for CKD replacement in (\%), versus the ratio of 287 days T.S. of CKD concrete samples in the literature to their corresponding control groups in (\%)

Table 6: 28 days tensile strength loss in CKD concrete up to 50\% CKD replacement amount, according to the prepared model equation.

\begin{tabular}{ll}
\hline CKD Replacement & $\begin{array}{l}\text { 28 Days Tensile Strength Loss in CKD Samples } \\
\text { According to The Prepared Model Equation }\end{array}$ \\
\hline $\mathbf{5 \%}$ & $4 \%$ \\
\hline $\mathbf{1 0} \%$ & $8 \%$ \\
\hline $\mathbf{1 5 \%}$ & $12 \%$ \\
\hline $\mathbf{2 0} \%$ & $17 \%$ \\
\hline $\mathbf{2 5 \%}$ & $21 \%$ \\
\hline $\mathbf{3 0} \%$ & $26 \%$ \\
\hline $\mathbf{4 0} \%$ & $31 \%$ \\
\hline $\mathbf{4 5 \%}$ & $37 \%$ \\
\hline $\mathbf{5 0} \%$ & $42 \%$ \\
\hline
\end{tabular}




\subsection{Days Flexural Strength}

The model prepared for the 28 days flexural strength data had an $\mathrm{R}^{2}$ of 0.92 , which means that the accuracy of the model trend is acceptable. The losses in 28 days flexural strength in CKD samples were less than that of compressive strength property as depicted in Figure 10. The optimal CKD replacement was $10 \%$, at which there was only $9 \%$ strength loss. The amount of strength losses up to $50 \%$ of CKD replacement is summarized in Table 7.

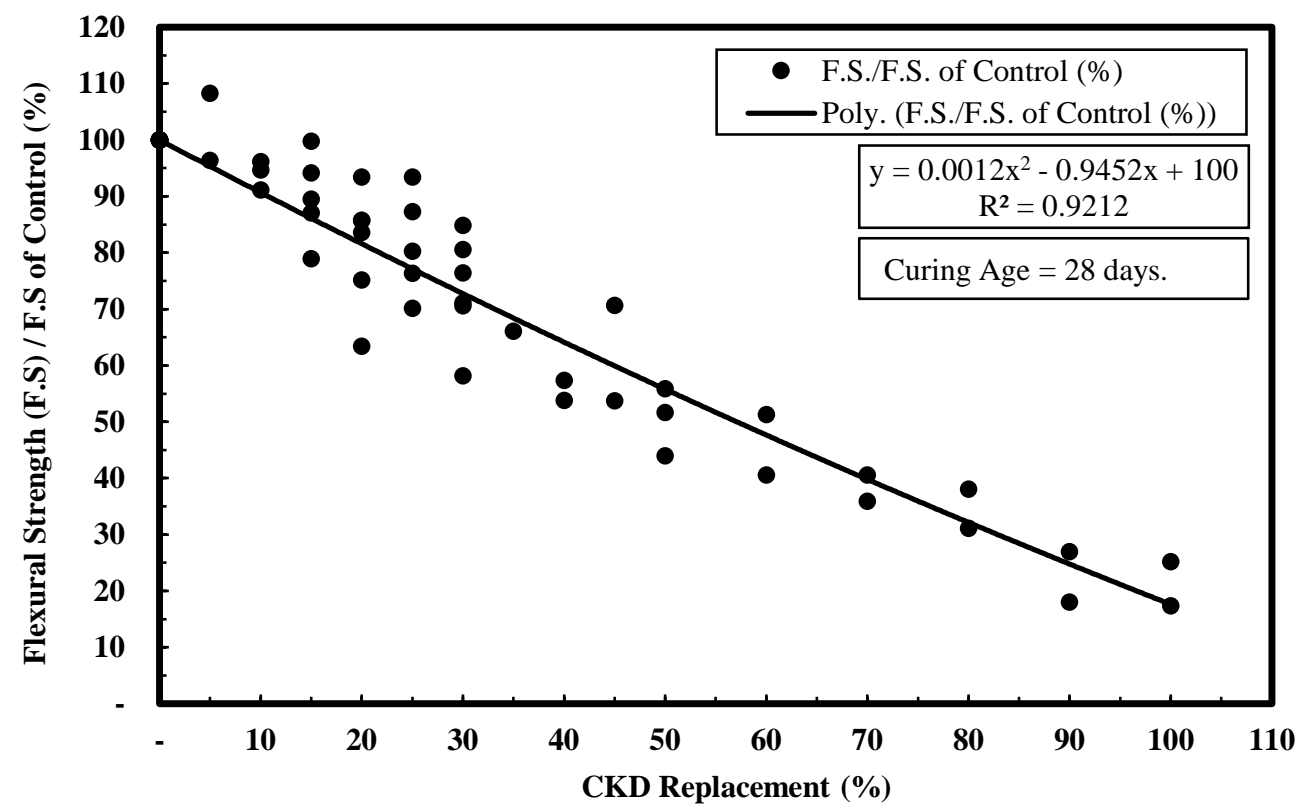

Figure 10: Trend line of the prepared model equation for CKD replacement in (\%), versus the ratio of 28 days F.S. of CKD concrete samples in the literature to their corresponding control groups in (\%)

Table 7: 28 days flexural strength loss in CKD concrete up to 50\% CKD replacement amount, according to the prepared model equation.

\begin{tabular}{ll}
\hline CKD Replacement & $\begin{array}{l}\text { 28 Days Flexural Strength Loss in CKD Samples } \\
\text { According to The Prepared Model Equation }\end{array}$ \\
\hline $\mathbf{5 \%}$ & $5 \%$ \\
\hline $\mathbf{1 0 \%}$ & $9 \%$ \\
\hline $\mathbf{1 5 \%}$ & $14 \%$ \\
\hline $\mathbf{2 0} \%$ & $18 \%$ \\
\hline $\mathbf{2 5 \%}$ & $23 \%$ \\
\hline $\mathbf{3 0} \%$ & $27 \%$ \\
\hline $\mathbf{3 5 \%}$ & $32 \%$ \\
\hline $\mathbf{4 5 \%}$ & $36 \%$ \\
\hline $\mathbf{5 0} \%$ & $40 \%$ \\
\hline
\end{tabular}




\subsection{Days Elastic Modulus}

The $\mathrm{R}^{2}$ of the prepared model for the 28 days elastic modulus data was at 0.9 , which means that the accuracy of the model trend is acceptable. The decreases in 28days elastic modulus in CKD samples were less than that of compressive strength property. The trend line was almost linear as depicted in Figure 11. The optimal amount of CKD replacement also can be considered as $10 \%$, at which the strength loss is at $8 \%$. The amount of strength losses up to $50 \%$ of CKD replacement is summarized in Table 8.

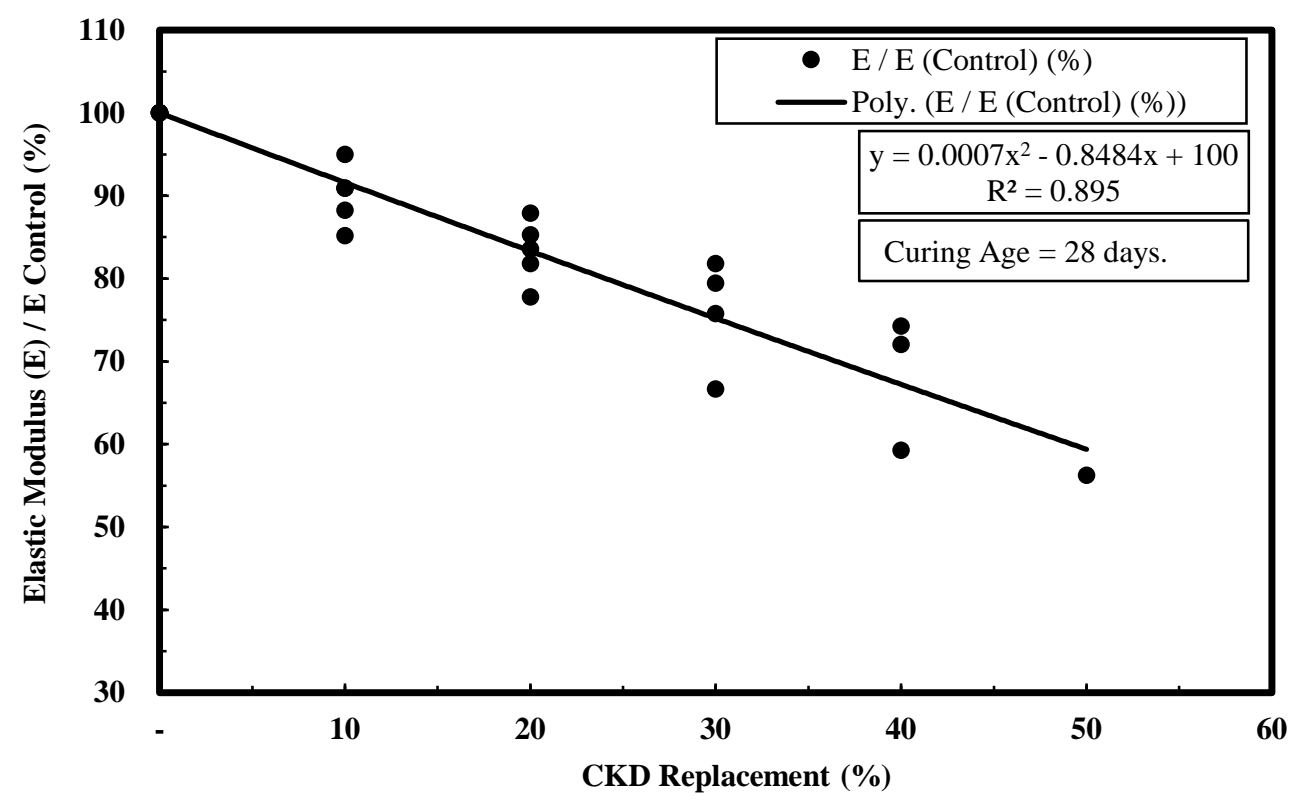

Figure 11: Trend line of the prepared model equation for CKD replacement in (\%), versus the ratio of 28 days E.M. of CKD concrete samples in the literature to their corresponding control groups in (\%)

Table 8: 28 days elastic modulus decrease in CKD concrete up to 50\% CKD replacement amount, according to the prepared model equation.

\begin{tabular}{ll}
\hline CKD Replacement & $\begin{array}{l}\text { 28 Days Elastic Modulus Loss in CKD Samples } \\
\text { According to The Prepared Model Equation }\end{array}$ \\
\hline $\mathbf{5 \%}$ & $4 \%$ \\
\hline $\mathbf{1 0 \%}$ & $8 \%$ \\
\hline $\mathbf{1 5 \%}$ & $13 \%$ \\
\hline $\mathbf{2 0} \%$ & $17 \%$ \\
\hline $\mathbf{2 5 \%}$ & $21 \%$ \\
\hline $\mathbf{3 0 \%}$ & $25 \%$ \\
\hline $\mathbf{3 5 \%}$ & $29 \%$ \\
\hline $\mathbf{4 0 \%}$ & $33 \%$ \\
\hline $\mathbf{4 5 \%}$ & $37 \%$ \\
\hline $\mathbf{5 0} \%$ & $41 \%$
\end{tabular}

In general, it can be said that the optimal amount of CKD content for normal concrete is at $10 \%$, at which the loss in mechanical properties of concrete is insignificant. The trend lines of all properties are of close form and patterns, as depicted in figure 12. 


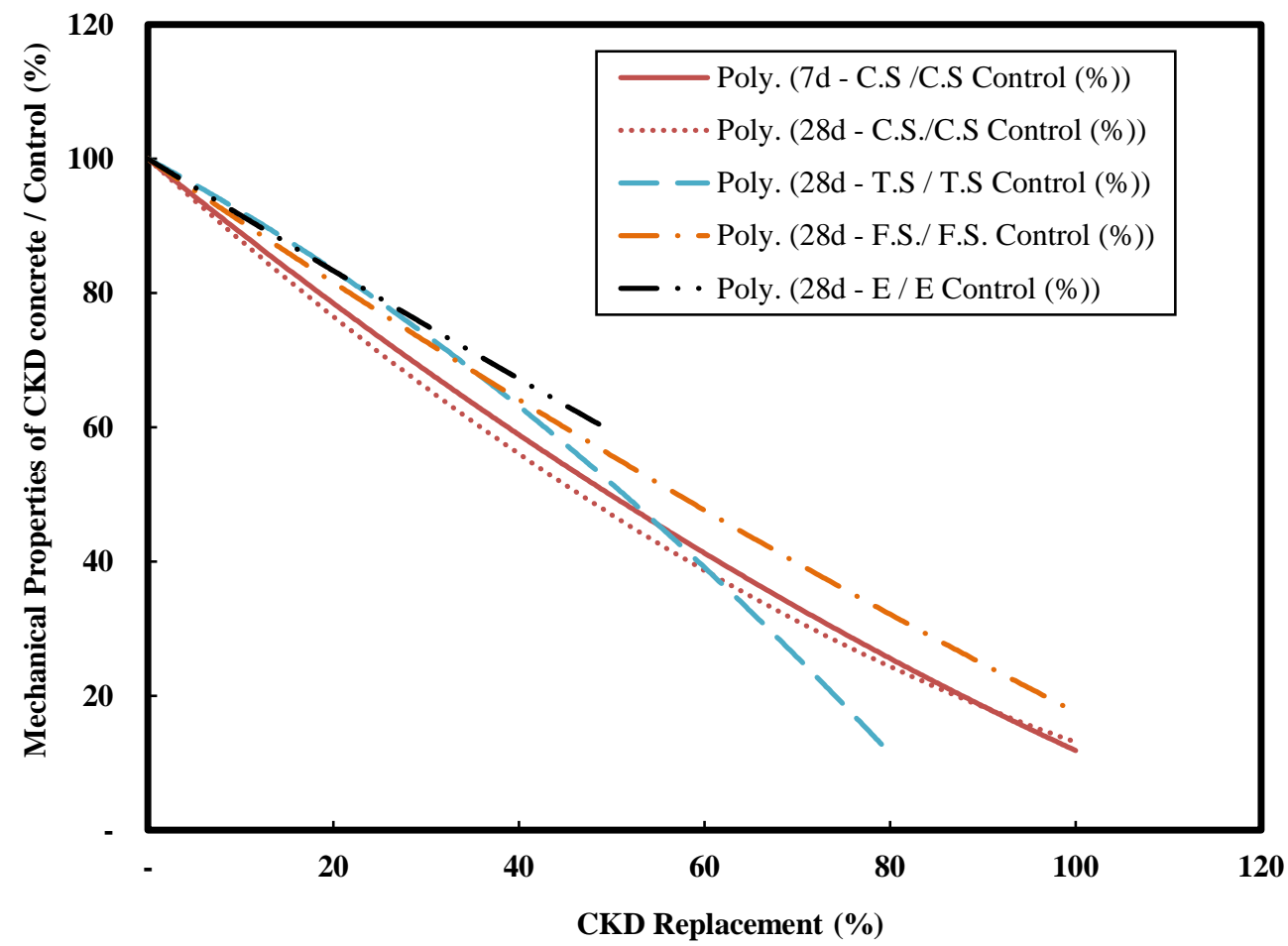

Figure 12: Comparison between model trend lines of CKD replacement, versus the ratio of mechanical properties of CKD concrete to those of corresponding control groups.

The first reason for the decrease in all properties of concrete against increases in CKD replacement can be related to the fact that CKD is not as a cementitious material as OPC or any other types of cement due to its different chemical composition. Table 9 summarizes the mechanical properties of all types of CKD used in the literature. The literature studies also related the loss in the mechanical properties of CKD concrete samples to poor formation of C$\mathrm{S}-\mathrm{H}$ due to alkalis, and weakening of the paste-aggregate bonds. Some researchers reported that there were less amount of decreases in the mechanical properties of CKD concrete at lower w/b ratios. The latter phenomenon was related to minimizing the occurrence probability of alkali silica reaction that happens in the presence of water [3, 21, 22]. Another reason for strength loss was reported to be the increase in chloride content, which is present in CKD. The latter crystallizes the products of hydration, resulting in opening a system of pores in the hardened samples. In addition, the chloride ions in CKD can participate in chemical reactions similar to those that involve sulfate ions and produce chloroaluminate hydrate (3CaO. $\mathrm{Al}_{2} \mathrm{O}_{3} \cdot \mathrm{CaCl}_{2} \cdot 12 \mathrm{H}_{2} \mathrm{O}$ ), that is equivalent to $3 \mathrm{CaO} \cdot \mathrm{Al}_{2} \mathrm{O}_{3} \cdot \mathrm{CaSO}_{4} \cdot 12 \mathrm{H}_{2} \mathrm{O}$ [23]. However, the action of chloroaluminate is different from sulphoaluminate as it causes softening [24]. Moreover, in the presence of Alkalis (high amounts of $\mathrm{SO}_{3}$ and $\mathrm{K}_{2} \mathrm{O}$ ), the microstructure of $\mathrm{CSH}$ phases becomes heterogeneous, therefore compressive strength decreases $[18,25]$. 
Table 9: Comparing the chemical properties of OPC cement with all CKD types used in literature.

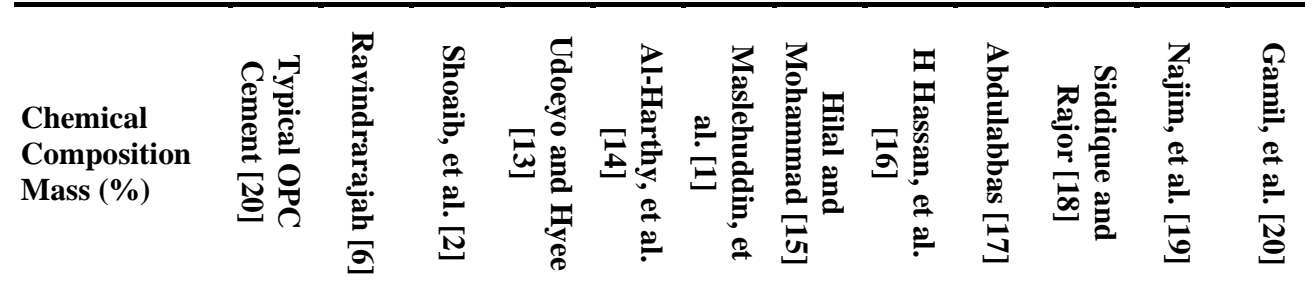

\begin{tabular}{lcccccccccccc}
\hline $\mathrm{SiO}_{2}$ & 21.6 & 12.2 & 11.95 & 2.16 & 15.8 & 17.1 & 14.82 & 15.53 & 15.46 & 13.17 & 18.9 & 17.3 \\
\hline $\mathbf{A l}_{2} \mathbf{O}_{3}$ & 6.2 & 5.8 & 1.12 & 1.09 & 3.6 & 4.24 & 5.52 & 3.83 & 3.41 & 2.38 & 4.19 & 3.81 \\
\hline $\mathbf{F e}_{2} \mathbf{O}_{3}$ & 3.13 & 2.3 & 2.45 & 0.54 & 2.8 & 2.89 & 1.98 & 3.05 & 3.05 & 2.62 & 3.25 & 2.99 \\
\hline $\mathbf{C a O}$ & 62.7 & 42.7 & 49.75 & 52.72 & 63.8 & 49.3 & 49.65 & 49.96 & 43.4 & 55.78 & 58.67 & 44.05 \\
\hline $\mathbf{M g O}$ & 1.48 & 13 & 1.86 & 0.68 & 1.9 & 1.14 & 3.35 & 1.69 & 2.98 & 0.69 & 1.87 & 2 \\
\hline $\mathbf{K}_{2} \mathbf{O}$ & 1.01 & 4.3 & 2.66 & 0.11 & 3 & 2.18 & - & - & 2.44 & 1.12 & 1.37 & 2.18 \\
\hline $\mathbf{N a}_{2} \mathbf{O}$ & 0.2 & 0.8 & - & - & 0.3 & 3.84 & - & - & 1.42 & - & 1.1 & - \\
\hline $\mathbf{S O}_{3}$ & 2.73 & 6.5 & 6.35 & - & 1.7 & 3.56 & 6.33 & 7.18 & - & 1.13 & 4.32 & 3.02 \\
\hline $\mathbf{P}_{2} \mathbf{O}_{2}$ & 0.21 & - & - & - & - & 0.12 & - & - & - & - & - & 1.22 \\
\hline $\mathbf{T i O}_{2}$ & 0.1 & - & - & - & - & 0.34 & - & - & - & - & - & 0.25 \\
\hline $\mathbf{C h l o r i d e}$ & 0 & - & - & - & - & 6.9 & - & - & 0.92 & - & 0.39 & - \\
\hline Free Lime & 1 & 6.1 & - & - & - & - & - & - & - & - & 19 & - \\
\hline Ignition Loss & 2.5 & 22.1 & 17.92 & 42.39 & - & 15.8 & - & 12.96 & 28.86 & - & 16.5 & - \\
\hline
\end{tabular}

The decreases in tensile \& flexural strength were mainly contributed to the CKD particles that do not offer strong bonds between aggregate and free OPC hydration phases that resemble cement mortar, leading to weaker bonds between the particles of aggregate and causing losses in tensile strength [2].

\section{CONCLUSION}

1. Replacing cement with CKD has detrimental effects on all mechanical properties of concrete, although no significant decreases occur in mechanical properties of concrete at 5\% CKD replacement.

2. Seven and 28 days compressive strengths of concrete decrease by increasing the amount of cement replacement with $\mathrm{CKD}$, depicting second-degree polynomial trends with $\mathrm{R}^{2}$ of 0.91 and 0.94 respectively.

3. The optimal amount of cement replacement from the compressive strength aspect is $10 \%$, at which there is $11 \%$ and $12 \%$ loss in 7 days and 28 days of curing age respectively.

4. Tensile and flexural strengths of concrete decrease with increasing CKD content, having second-degree polynomial trends with $\mathrm{R}^{2} \mathrm{~s}$ of 0.88 and 0.92 respectively.

5. Elastic modulus of concrete decrease by increasing the amount of cement replacement with CKD, having a second-degree polynomial trend with an $\mathrm{R}^{2}$ of 0.9 .

6. The optimal amount of CKD from tensile, flexural, and modulus of elasticity aspects is $10 \%$ by cement weight, at which there are $8 \%, 9 \%$, and $8 \%$ decreases respectively. 


\section{REFERENCES}

[1] M. Maslehuddin, O. Al-Amoudi, M. Rahman, M. Ali, and M. Barry, "Properties of cement kiln dust concrete," Construction and Building Materials, vol. 23, no. 6, pp. 2357-2361, 2009.

[2] M. Shoaib, M. Balaha, and A. Abdel-Rahman, "Influence of cement kiln dust substitution on the mechanical properties of concrete," cement \& concrete research, vol. 30, no. 3, pp. 371-377, 2000.

[3] R. Siddique, "Utilization of cement kiln dust (CKD) in cement mortar and concrete-an overview," Resources, conservation and recycling, vol. 48, no. 4, pp. 315-338, 2006.

[4] M. Maslehuddin, O. Al-Amoudi, M. Shameem, M. Rehman, and M. Ibrahim, "Usage of cement kiln dust in cement products-research review and preliminary investigations," Construction and Building Materials, vol. 22, no. 12, pp. 2369-2375, 2008.

[5] R. J. Collins and J. Emery, "Kiln dust-fly ash systems for highway bases and subbases," United States. Federal Highway Administration1983.

[6] R. S. Ravindrarajah, "Usage of cement kiln dust in concrete," International Journal of Cement Composites and Lightweight Concrete, vol. 4, no. 2, pp. 95-102, 1982.

[7] C. Aidan and C. Trevor, "Cement kiln dust," Concrete (London), vol. 29, pp. 40-42, 1995.

[8] S. A. Meo, "Health hazards of cement dust," Saudi Med J, vol. 25, no. 9, pp. 1153-1159, 2004.

[9] L. Coppola, D. Coffetti, and E. Crotti, "Plain and ultrafine fly ashes mortars for environmentally friendly construction materials," Sustainability, vol. 10, no. 3, p. 874, 2018.

[10] P. Edwards. (2017, 4 December 2017) Global cement top 100 report 2017-2018. Global Cement Magazine. 12-20.

[11] F. Schorcht, I. Kourti, B. M. Scalet, S. Roudier, and L. D. Sancho, "Best available techniques (BAT) reference document for the production of cement, lime and magnesium oxide," European Commission Joint Research Centre Institute for Prospective Technological Studies, Luxembourg2013.

[12] U. S. E. P. Agency, "Report to congress on cement kiln dust," U.S.1993, vol. 5.

[13] F. F. Udoeyo and A. Hyee, "Strengths of cement kiln dust concrete," Journal of Materials in Civil Engineering, vol. 14, no. 6, pp. 524-526, 2002.

[14] A. S. Al-Harthy, R. Taha, and F. Al-Maamary, "Effect of cement kiln dust (CKD) on mortar and concrete mixtures," Construction and Building Materials, vol. 17, no. 5, pp. 353-360, 2003.

[15] N. N. Hilal and A. M. Mohammad, "Re-using The By-product of Cement Industry (Cement Kiln Dust) To Produce The Concrete," Anbar Journal of Engineering Sciences, vol. 3, no. 2, 2010.

[16] I. H Hassan, O. M Abdul-Kareem, and A. Yasin Shihab, "Utilization of Cement Kiln Dust (CKD) as a Partial Replacement of Cement in Mortar and Concrete," AL-Rafdain Engineering Journal, vol. 21, no. 6, pp. 7287, 2013.

[17] Z. H. Abdulabbas, "Utilization of cement kiln dust in concrete manufacturing," Jordan Journal of Civil Engineering, vol. 7, no. 1, pp. 2012-2014, 2013.

[18] R. Siddique and A. Rajor, "Influence of bacterial treated cement kiln dust on the properties of concrete," Construction and building materials, vol. 52, pp. 42-51, 2014.

[19] K. B. Najim, I. Al-Jumaily, and A. M. Atea, "Characterization of sustainable high performance/selfcompacting concrete produced using CKD as a cement replacement material," Construction and Building Materials, vol. 103, pp. 123-129, 2016.

[20] Y. Gamil, I. Bakar, and L. Y. Loon, "Utilization of Normal and Treated Cement Kiln Dust as Cement Replacement Materials in Concrete," Pertanika Journal of Science and Technology, vol. 27, no. 1, 2019.

[21] D. Hobbs, J. Bensted, and P. Barnes, "Alkali-silica reaction in concrete," Structure and Performance of Cements, pp. 265-281, 2002.

[22] R. N. Swamy, The alkali-silica reaction in concrete. CRC Press, 1991.

[23] J. Bensted, "Hydration of Portland cement," Advances in cement technology, pp. 307-347, 1983.

[24] I. Biczok and N. Blasovszky, Concrete corrosion and concrete protection. United States: Chemical Publishing Co., 1964, p. 543.

[25] I. Jawed and J. Skalny, "Alkalies in cement: a review: II. Effects of alkalies on hydration and performance of Portland cement," Cement and concrete research, vol. 8, no. 1, pp. 37-51, 1978. 